\section{Half as many radiologists again by 1995}

In 1979 a $B M 7$ leading article stated that "diagnostic imaging must improve its image, attract more candidates, and . . . ensure the best clinical value is obtained from a specialty whose capacity will never be sufficient to meet demand." Seven years on the Royal College of Radiologists can be pleased to have seen the first two objectives achieved and to have made much progress with the third.

Yet manpower problems remain. Demand continues to exceed capacity, and progress in technology has accentuated the discrepancy. The past decade has seen the wide application of sonar scanning and the proliferation of scintiscanning and computed tomography. Now interventional and therapeutic radiology - when one radiologist may spend a whole session with one patient-are developing rapidly, and the future promises more of the same with magnetic resonance imaging, Doppler sonar, and mammography screening.

The college is concerned primarily with professional standards and knows that if additional work is absorbed by a static work force then standards will fall. It has produced a report detailing and quantifying the work that a radiologist may be expected to undertake. ${ }^{2}$ Taking a look into the future and casting an envious glance abroad, it has estimated a need to increase the numbers of consultants by half by 1995 .

Professional work is notoriously difficult to quantify. The number of attendances of patients for radiology makes no allowance for multiple examinations. Total examinations are easy to count (and administrators and authorities understand the concept) but make no allowance for the wide variation in radiologist effort needed (though the case mix is fairly steady and does allow some wide comparisons). For many years work in radiology departments has been counted in radiographic work units based on the time a patient is in the examination room, while the college has had a points system based on the radiologists' time required for each examination.

Next year sees the implementation in radiology of the Körner report. ${ }^{3}$ The college has modified its workload measurement system and allied it to the Körner examination groups, weighting each group according to the radiologists' involvement. This is not always satisfactory-for instance, obstetric sonar does not often keep the consultant radiologist busy for $\mathbf{1 0}$ minutes-and no account is taken of films not reported for whatever reason. Expansion of radiology is unlikely to result from this college initiative alone. When demand exceeds capacity the only practical solution, if standards are to be maintained, is to make less urgent problems wait. ${ }^{4}$ If the wait is unacceptable to other doctors and health authorities then they may choose to put more resources into radiology. Meanwhile, radiologists must see that limited resources are used to the best advantages for the community while continuing to encourage the introduction of the best of new technologies and techniques.

The work of the college, ${ }^{5-7}$ the World Health Organisation, ${ }^{8}$ and individual radiologists 9 must also encourage elimination of relatively unnecessary radiology. Then we may be able to offer new radiological procedures without detriment to the many patients whose diagnosis is still made from simple radiographs ${ }^{10}$ - even if the college manpower target is not met.

Consultant Radiologist,

Queen Elizabeth Hospital

M J BRINDLE

King's Lynn PE30 4ET
1 Anonymous. A critical time for diagnostic imaging [Editorial]. Br Med 7 1979;ii:690-1.

2 Royal College of Radiologists. Assessment of workload and manpower in diagnostic radiology and in radiotherapy and oncology. London: Royal College of Radiologists, 1986.

3 National Health Service and Department of Health and Social Security Steering Group on Health Services Information. First Report. London: HMSO, 1982.

4 Brindle MJ. Radiology workload-a solution Br Med J 1978;ii:514-5.

5 Royal College of Radiologists. Pre-operative chest radiography. A national study. Lancet 1979;ii:83-6.

6 Royal college of Radiologists. Patient selection for skull radiography in uncomplicated head injury. A national study. Lancet 1983;i:115-8.

7 Royal College of Radiologists Working Party. Radiography of injured arms and legs in eight accident and emergency units in England and Wales. Br Med f 1985;291:1325-8.

8 World Health Organisation. A rutional approuch to radiodiagnostic investigations. Geneva: World Health Organisation, 1983. (Technical Report Series No 689.)

Health Organisation, 1983. (Technical Report Series No 689.)
de Lacey G. How to make the best use of your x-ray department. Hospital Update 1983; 4 (Apr):455-66.

10 Steiner RE. New imaging techniques: their relation to conventional radiology. Br Med $\mathrm{J}$ 1982;284: 1590-2

\section{Urinary tract infection in the elderly}

Bacteriuria $\left(10^{5}\right.$ bacteria in $1 \mathrm{ml}$ of urine) is common in the elderly, but how much it matters and whether it should be treated are unclear. Its importance in the elderly may be quite different from that in the young: the association with dysuria and frequency is poor ${ }^{1-3}$; fever is often absent; and there are no pus cells in a third of specimens from elderly patients with bacteriuria. ${ }^{4}$ Using significant bacteriuria as the main criterion for urinary tract infection thus has limitations.

"Significant bacteriuria" is a statistical concept that was introduced by $\mathrm{Kass}^{5}$ to distinguish contamination of urine specimens during collection from the presence of bacteria in bladder urine. It applies to those who have no urinary symptoms and from whose urine Escherichia coli or Proteus is isolated in pure growth and may not be applicable in those with symptoms or infection with other organisms.

Community studies show that about a fifth of elderly women and $10 \%$ of elderly men have significant bacteriuria, and the prevalence probably increases with age in both sexes. ${ }^{126}$ Lowest prevalences are found in the elderly living independently and the highest in patients in long stay geriatric wards.?

Bacteriuria in the elderly does seem to be related to mortality, ${ }^{810}$ but it may be a marker for other diseases that are the primary causes of increased mortality rather than itself being the direct cause. A recent study that controlled for age and coexisting disease seemed to confirm this epiphenomenal relation. ${ }^{10}$

It has often been assumed that bacteriuria in the elderly, particularly in women, represents bladder rather than upper urinary tract infection, and is hence benign. One study, however, showed that over half of urinary infections in elderly women in hospital may be in the upper urinary tract. ${ }^{11}$ Diminished glomerular filtration rate and renal plasma flow have been reported in elderly patients with bacteriuria, ${ }^{12}$ but whether the bacteriuria is a primary cause of renal damage or secondary to it is unknown.

It is thus difficult to draw practical conclusions from available research on how best to treat old people with bacteriuria. Examination for bacteriuria is usually undertaken in an elderly patient because she has one of Isaac's "giants of geriatrics"-immobility, instability, incontinence, and intellectual deterioration. ${ }^{13}$ The detection of bacteriuria then leads almost inevitably to treating the "infection" because it may be causing the atypically presenting disease. In geriatric wards about one third of all courses of anti- 